LETTER TO JMG

\title{
Primary open angle glaucoma is associated with a specific p53 gene haplotype
}

\author{
T Ressiniotis, P G Griffiths, M Birch, S Keers, P F Chinnery
}

J Med Genet 2004;41:296-298. doi: 10.1136/jmg.2003.016089

$\mathrm{P}$ rimary open angle glaucoma (POAG) is the second commonest cause of blind registration in the United Kingdom and affects approximately 70 million people worldwide. ${ }^{12}$ The major risk factors are intraocular pressure, ethnicity, refractive errors, and vascular function. There is also clear evidence from population, case control, and twin studies of a heritable element to POAG. ${ }^{3}{ }^{4}$ The genes encoding myocilin and optineurin have been be linked to POAG in large families with autosomal dominant inheritance, and a number of chromosomal loci are being studied for a possible genetic association with glaucoma. ${ }^{5-10}$ It appears that POAG is a complex trait and multiple genes contribute to the phenotype and increase individuals' susceptibility to glaucomatous optic neuropathy.

Quite independently, a number of recent studies suggest that apoptosis of the retinal ganglion cells is an important mechanism behind glaucoma. ${ }^{11}{ }^{12}$ Apoptosis is a form of genetically controlled, programmed cell death, which is under extensive research, especially in cancer, ${ }^{13-15}$ neuronal injury, ${ }^{16}$ and neurodegenerative disorders. ${ }^{17}{ }^{18}$ During the primary regulatory steps of apoptosis, a signal of cellular distress activates the tumour suppressor protein p53. This protein acts like a "guardian of the genome", regulating subsequent apoptotic events through several oncogenes, principally bax and $b c l-2 .{ }^{13}$ Further apoptotic events include changes in mitochondria with cytochrome $c$ release and activation of cystein proteases (caspases), which digest the dying cell from within. ${ }^{19}$

It is therefore of great interest that one study showed an association between genetic polymorphic variants of the $p 53$ gene and POAG. In a Chinese study, a cytosine $(\mathrm{C})$ residue at codon 72 of the $p 53$ gene was significantly more common in POAG patients than control subjects. ${ }^{20}$ In another study carried out on an Indian cohort, a second polymorphism (a 16 bp duplication in intron 3 of p53) was also studied, but neither genetic variant was associated with $\mathrm{POAG},{ }^{21}$ raising questions about their role in POAG. In order to clarify these issues, we studied both polymorphisms in a larger cohort of carefully characterised cases and controls, matched and selected from the same Caucasian population. Rather than focussing on the individual polymorphisms that may not have any direct functional consequences, we studied the $p 53$ haplotype to determine whether natural genetic variants in this gene contribute to the risk of developing POAG.

\section{METHODS}

\section{Case and control ascertainment}

Having obtained approval from our local research ethics committee, blood samples were analysed from an unrelated Caucasian cohort of 140 POAG patients and 73 healthy individuals, matched for age and gender, from the north east area of England. POAG patients underwent Goldmann tonometry, slit lamp biomicroscopy of the optic discs, Humphrey full threshold 24:2 visual fields, and four mirror gonioscopy. Controls underwent the same examination,

\section{Key points}

- Apoptosis of retinal ganglion cells has been implicated in the pathogenesis of primary open angle glaucoma (POAG). Specific genes regulate apoptosis, including p53, which codes for a tumour suppressor protein. Two studies looking at the association of specific polymorphisms in the p53 gene and POAG revealed conflicting results, and the role of p53 in POAG remains uncertain. To address this issue we studied p53 gene haplotypes in a larger group of carefully phenotyped adults with POAG and matched controls from the same Caucasian population.

- A total of 140 unrelated POAG patients (mean age 73 years, SD 8.01) and 73 unrelated healthy matched controls (mean age 78 years, SD 4.40) were studied. POAG was defined by characteristic cupping of the optic disc, open iridocorneal angle, and typical glaucomatous visual field defects. Secondary causes of glaucoma were excluded, and controls had normal intraocular pressure, visual fields, and optic discs. Patients and controls were genotyped for two p53 polymorphisms (a 16 base pair insertion in intron 3 , and a $C$ to $G$ substitution at codon 72 in exon 4 which changes an arginine to a proline residue). Haplotypes were determined using a statistical algorithm.

- We observed a significant difference in the p53 haplotype distribution between cases and controls $(p<0.0001)$. Subgroup analysis revealed the source of this difference. For individuals with the p53 insertion polymorphism, an arginine at codon 72 was significantly more common in patients than controls $(p<0.0001)$.

- These findings suggest a potential role for p53 and apoptosis in POAG.

omitting gonioscopy and substituting suprathreshold fields for full threshold fields.

POAG was defined as characteristic cupping of the optic disc, open iridocorneal angle, and typical glaucomatous visual field defects. Patients with secondary types of glaucoma were excluded.

\section{Genomic DNA genotyping}

After total genomic DNA extraction, a region of the $p 53$ gene was amplified by polymerase chain reaction (PCR). For each sample, $1 \mu \mathrm{l}$ of DNA was mixed with $1 \mathrm{U}$ Taq DNA

Abbreviations: $P C R$, polymerase chain reaction; POAG, primary open angle glaucoma 
polymerase (Promega), $10 \times$ Promega buffer, $2 \mathrm{mmol}$ dNTP, $0.25 \mu \mathrm{M}$ of each oligonucleotide (primer), and $\mathrm{H}_{2} \mathrm{O}$ to a total volume of $30 \mu \mathrm{l}$. The primers used were: forward: 5'-CCT GAA AAC AAC GTT CTG GTA A -3'; and reverse: 5'-GCA TTG AAG TCT CAT GGA AG - $3^{\prime}$. The forward primer was fluorescently labelled at the $5^{\prime}$ end with Dye 3 (Proligo). Cycling conditions were: $94^{\circ} \mathrm{C}$ for 4 min followed by 35 cycles of $94^{\circ} \mathrm{C}$ for $1 \mathrm{~min}, 55^{\circ} \mathrm{C}$ for $1 \mathrm{~min}, 72^{\circ} \mathrm{C}$ for $1 \mathrm{~min}$, and a final incubation of $72^{\circ} \mathrm{C}$ for $10 \mathrm{~min}$. The full length PCR product was $432 \mathrm{bp}$ in the absence of the $16 \mathrm{bp}$ duplication, and $448 \mathrm{bp}$ in the presence of the $16 \mathrm{bp}$ duplication. A $10 \mu \mathrm{l}$ sample of each PCR product was digested with $5 \mathrm{U}$ of the restriction enzyme BstUI (New England Biolabs), $2 \mu$ l buffer (NEB Buffer 2), and $\mathrm{H}_{2} \mathrm{O}$ to a total volume of $20 \mu \mathrm{l}$ per sample for $12 \mathrm{~h}$ at $60^{\circ} \mathrm{C}$. Restriction fragment length polymorphism analysis was performed with the CEQ 8000 Genetic System Analysis instrument (Beckman Coulter). A $1.5 \mu \mathrm{l}$ aliquot of the incubated product per sample was added to a mix of $0.5 \mu \mathrm{l}$ of DNA marker (600 size) and $25 \mu \mathrm{l}$ of sample loading solution.

DNA fragments with a $\mathrm{G}$ at codon 72 (corresponding to an arginine residue) contained the restriction site BstUI, resulting in a fragment of 248 or $232 \mathrm{bp}$ depending on whether the $16 \mathrm{bp}$ duplication was present or absent. DNA fragments with a $\mathrm{C}$ at codon 72 (corresponding to a proline residue) lacked the BstUI restriction site, resulting in fragments of 448 or $432 \mathrm{bp}$ depending on the presence or absence of the 16 bp duplication (fig 1). p53 gene haplotypes were determined for the POAG patients and controls using a well-established mathematical algorithm (PHASE version 1.0.1, obtained from the Oxford Mathematical Genetics Group through http://archimedes.well.ox.ac.uk/). ${ }^{22}$ The frequencies of the four haplotypes were compared using chisquared analysis. Limited subgroup analyses were performed using Fisher's exact test. ${ }^{23}$

\section{RESULTS}

Our cohort consisted of 140 POAG patients and 73 controls. The proportion of females in the POAG group was not significantly different from the control group $\left(\chi^{2}=1.66\right.$, $p=0.20)$. The median age was 73 years for the POAG patients (range 51-87, SD 8.01) and 78 years for the controls (range 68-90, SD 4.4), and the mean age of the controls was significantly greater than that of the POAG patients (Student's $t$ test $=9.0, \mathrm{p}<0.001$ ). Mean intraocular pressure
(IOP) was $20.8 \mathrm{mmHg}$ for the patients (SD 2.6) and $16.2 \mathrm{mmHg}$ for the controls (SD 3.4). Median cup:disc ratio was 0.8 and 0.3 for patients and controls, respectively. The frequencies of the four haplotypes are illustrated in table 1.

Chi-squared analysis revealed a significant difference in the $p 53$ haplotype distribution between cases and controls $\left(\chi^{2}=37.84, \mathrm{p}<0.0001\right)$. We then studied the distribution of the haplotypes within the different subgroups. For individuals that did not harbour the $p 53$ duplication polymorphism, the frequency of the $\mathrm{G}$ or $\mathrm{C}$ residues at codon 72 was not significantly different between cases and controls (Fisher's exact test, $\mathrm{p}=0.15$ ). By contrast, for individuals with the $p 53$ duplication polymorphism, an arginine at codon 72 was significantly more common in patients than controls (Fisher's exact, $\mathrm{p}<0.0001$ ). No additional statistical analyses were carried out.

\section{DISCUSSION}

POAG is a complex neurodegenerative disease with evidence of a hereditary element. The pathogenetic factors involved in ganglion cell death have not yet been fully explained. Apoptosis has been suggested as a mechanism of glaucomatous neuropathy. The evidence for this hypothesis is based on the presence of characteristic histological and biochemical features in experimental glaucoma and animal studies, including "apoptotic bodies", DNA fragmentation, and digestion of the dying cells from the surrounding cells, in the absence of inflammatory response. ${ }^{24} 25$

Table 1 Frequency distribution of $p 53$ codon 72 polymorphic haplotypes in POAG patients and healthy subjects

\begin{tabular}{lll}
\hline & Controls & POAG \\
\hline Del-pro & 106 & 216 \\
& $72.60 \%$ & $77.14 \%$ \\
Del-arg & 20 & 23 \\
& $13.69 \%$ & $8.21 \%$ \\
Ins-arg & 1 & 35 \\
& $0.68 \%$ & $12.50 \%$ \\
Ins-pro & 19 & 6 \\
& $13.01 \%$ & $2.14 \%$ \\
\hline
\end{tabular}

"Ins" and "Del" indicate the presence or absence of the $16 \mathrm{bp}$ duplication on intron 3, respectively. "arg" and "pro" stand for encoding of arginine and proline from the polymorphic site on exon 4.

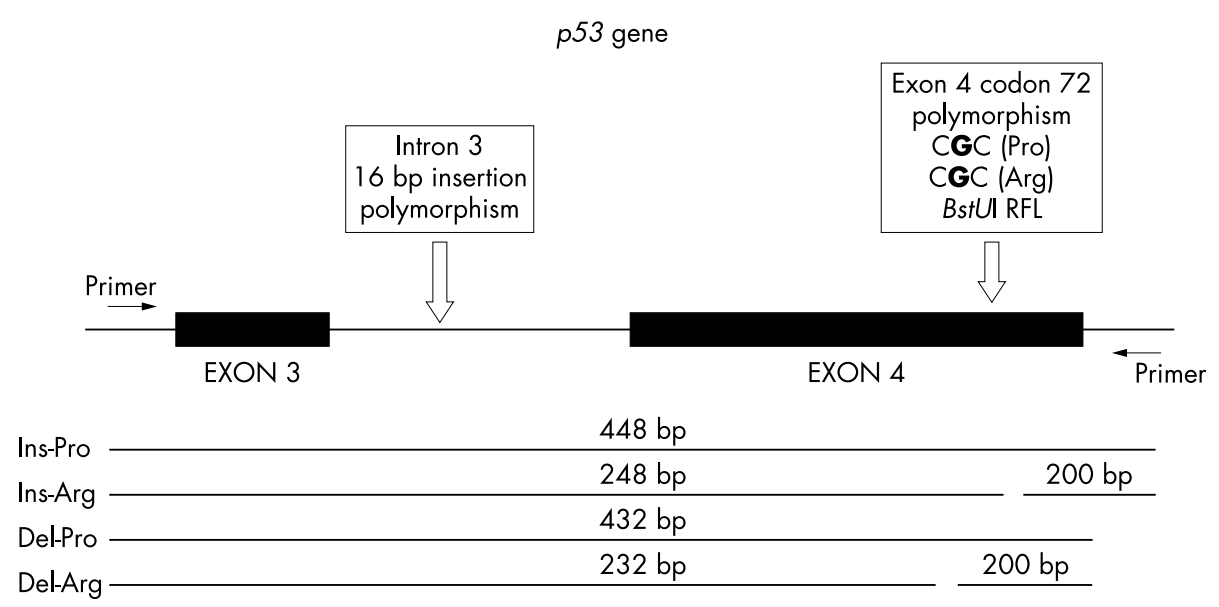

Figure 1 Diagram showing the amplified area of p53 gene and the studied polymorphic sites (arrows); there is a 16 bp insertion in intron 3 and a base change from $C$ at exon 4 (corresponding to a proline residue) to $G$ (corresponding to an arginine residue, introducing the BstU I restriction site). Schematic representations of the four possible DNA fragments emerging after BstU I digestion are shown. "Ins" and "Del" represent the presence or absence of the 16 bp insertion in intron 3, respectively. "Arg" and "Pro" stand for encoding of arginine and proline from the polymorphic site on exon 4. RFLP, restriction fragment length polymorphism. 
The $p 53$ gene encodes the tumour suppressor protein $\mathrm{p} 53$, which determines crucial events in the apoptotic cascade by regulating other oncogenes. Mutations of the $p 53$ gene, which is located on the short arm of chromosome 17, have been detected in almost $50 \%$ of human malignancies. ${ }^{26}$ The mutant or inactivated p53 protein fails to initiate the apoptotic process and, consequently, genetically damaged cells proliferate in an uncontrolled manner. ${ }^{14}$ By contrast, in neurodegenerative processes ${ }^{17}{ }^{18}$ and toxic neuronal injury, ${ }^{16}$ the $p 53$ gene is up-regulated in response to cellular stress, thereby promoting cell death through apoptosis. This raises the possibility that functional genetic variants of $p 53$ influence the rate of neuronal cell loss in a number of neurodegenerative disorders, including POAG.

In our study, we have found a highly significant difference in the $p 53$ haplotype distribution between controls and POAG. Subgroup analysis revealed that this was because individuals with the 16 bp insertion in intron 3 were far more likely to have an arginine residue than a proline residue at codon 72 if they had POAG (the insertion-arginine haplotype). These findings add further weight to the growing body of evidence implicating apoptosis in glaucoma, and suggest that genetic variation in the $p 53$ gene is one of the many factors contributing to the aetiology of the disorder.

How can we explain the discrepancy between two previous conflicting reports ${ }^{20}{ }^{21}$ and the current study? First, our study was based upon a larger cohort of well-characterised cases and controls. This approach minimises the chance of a false positive result (type I error), to which genetic association studies are particularly prone. ${ }^{27}$ Second, we cannot exclude the possibility that the different ethnic origins of the study groups are responsible for the disparity in the molecular results. In most cases POAG is thought to arise through a complex interaction of genes with the environment, and different environmental factors, coupled with differences in the genetic background, could alter the relative contribution of $p 53$ polymorphisms in POAG. ${ }^{28}$ Finally, our analytical approach was fundamentally different to the other two studies. We determined $p 53$ gene haplotypes in cases and controls, and identified a particular $p 53$ haplotype that was strongly associated with POAG. By contrast, the two previous studies independently looked for an association with particular alleles within the p53 gene. This suggests that neither polymorphism is the actual genetic variant that determines the increased risk of POAG, hence the conflicting data in the two previous studies, and that the true functional variant is in linkage disequilibrium with the insertionarginine haplotype identified in this study. Further analysis of this haplotype will hopefully lead to the identification of the actual DNA sequence that has functional consequences and is responsible for the haplotype association, which may lie in the non-coding regulatory region of the gene.

\section{ACKNOWLEDGEMENTS}

We would like to thank Mr Richard Andrews for his contribution to the above work. PFC is a Wellcome Trust Senior Fellow in Clinical Science.

\footnotetext{
Authors' affiliations

T Ressiniotis, P G Griffiths, M Birch, Department of Ophthalmology, Royal Victoria Infirmary, Newcastle upon Tyne, UK

T Ressiniotis, S Keers, P F Chinnery, Department of Neurology, Medical School, The University of Newcastle upon Tyne, Newcastle upon Tyne, UK

This study was funded by educational grants from Pharmacia and Special Trustees of the Newcastle upon Tyne Hospitals NHS Trust, UK. Conflict of interest: none declared.
}

Correspondence to: P G Griffiths, FRCOphth, Senior Lecturer and Consultant Ophthalmologist, Royal Victoria Infirmary, Queen Victoria Road, Newcastle upon Tyne, NE1 4LP, UK; p.g.griffiths@ncl.ac.uk

Received 1 November 2003

Accepted for publication 28 January 2004

\section{REFERENCES}

1 Klein BE, Klein R, Sponsel WE, Franke T, Cantor LB, Martone J, Menage WJ. Prevalence of glaucoma. The Beaver Dam Eye Study. Ophthalmology 1992;99:1499-504.

2 Quigley HA, Vitale S. Models of open-angle glaucoma prevalence and incidence in the United States. Invest Ophthalmol Vis Sci 1997;38:83-91.

3 Lichter PR. Genetic clues to glaucoma's secrets. The L Edward Jackson Memorial Lecture. Part 2. Am J Ophthalmol 1994;1 17:706-27.

4 WuDunn D. Genetic basis of glaucoma. Curr Opin Ophthalmol 2002; 13:55-60.

5 Sarfarazi M, Child A, Stoilova D, Brice G, Desai T, Trifan OC, Poinoosawmy D, Crick RP. Localization of the fourth locus (GLC1E) for adultonset primary open-angle glaucoma to the 10p15-p14 region. Am J Hum Genet 1998;62:641-52.

6 Colomb E, Nguyen TD, Bechetoille A, Dascotte JC, Valtot F, Brezin AP, Berkani M, Copin B, Gomez L, Polansky JR, Garchon HJ. Association of a single nucleotide polymorphism in the TIGR/MYOCILIN gene promoter with the severity of primary open-angle glaucoma. Clin Genet 2001;60:220-5.

7 Stoilova D, Child A, Trifan OC, Crick RP, Coakes RL, Sarfarazi M. Localization of a locus (GLC1B) for adult-onset primary open angle glaucoma to the 2cenq13 region. Genomics 1996;36:142-50.

8 Stone EM, Fingert JH, Alward WL, Nguyen TD, Polansky JR, Sunden SL, Nishimura D, Clark AF, Nystuen A, Nichols BE, Mackey DA, Ritch R, Kalenak JW, Craven ER, Sheffield VC. Identification of a gene that causes primary open angle glaucoma. Science 1997;275:668-70.

9 Wirtz MK, Samples JR, Kramer PL, Rust K, Topinka JR, Yount J, Koler RD, Acott TS. Mapping a gene for adult-onset primary open-angle glaucoma to chromosome 3q. Am J Hum Genet 1997;60:296-304

10 Wirtz MK, Samples JR, Rust K, Lie J, Nordling L, Schilling K, Acott TS, Kramer PL. GLC1F, a new primary open-angle glaucoma locus, maps to 7q35-q36. Arch Ophthalmol 1999;117:237-41.

11 Nickells RW. Apoptosis of retinal ganglion cells in glaucoma: an update of the molecular pathways involved in cell death. Surv Ophthalmol 1999;43(suppl 1):S151-61.

12 Osborne NN, Wood JP, Chidlow G, Bae JH, Melena J, Nash MS. Ganglion cell death in glaucoma: what do we really know? $\mathrm{Br} J$ Ophthalmol 1999;83:980-6.

13 Smith ND, Rubenstein JN, Eggener SE, Kozlowski JM. The p53 tumor suppressor gene and nuclear protein: basic science review and relevance in the management of bladder cancer. J Urol 2003;169:1219-28.

14 Sekido Y, Fong KM, Minna JD. Molecular genetics of lung cancer. Annu Rev Med 2003;54:73-87

15 Sheets EE, Yeh J. The role of apoptosis in gynaecological malignancies. Ann Med 1997;29:121-6.

16 Morrison RS, Kinoshita Y, Johnson MD, Guo W, Garden GA. p53-dependent cell death signaling in neurons. Neurochem Res 2003;28:15-27.

17 Shahbazian MD, Orr HT, Zoghbi HY. Reduction of Purkinje cell pathology in SCA1 transgenic mice by p53 deletion. Neurobiol Dis $2001 ; 8: 974-81$.

18 LaFerla FM, Hall CK, Ngo L, Jay G. Extracellular deposition of beta-amyloid upon p53-dependent neuronal cell death in transgenic mice. J Clin Invest 1996;98:1626-32.

19 Levine AJ. p53, the cellular gatekeeper for growth and division. Cell 1997;88:323-31.

20 Lin HJ, Chen WC, Tsai FJ, Tsai SW. Distributions of p53 codon 72 polymorphism in primary open angle glaucoma. $\mathrm{Br} J$ Ophthalmol 2002;86:767-70.

21 Acharya M, Mitra S, Mukhopadhyay A, Khan M, Roychoudhury S, Ray K. Distribution of p53 codon 72 polymorphism in Indian primary open angle glaucoma patients. Mol Vis 2002;8:367-71.

22 Stephens M, Smith NJ, Donnelly P. A new statistical method for haplotype reconstruction from population data. Am J Hum Genet $2001 ; 68: 978-89$.

23 Altman D. Practical statistics for medical research. London: Chapman and Hall, 1997.

24 Quigley HA, Nickells RW, Kerrigan LA, Pease ME, Thibault DJ, Zack DJ. Retinal ganglion cell death in experimental glaucoma and after axotomy occurs by apoptosis. Invest Ophthalmol Vis Sci 1995;36:774-86.

25 Okisaka S, Murakami A, Mizukawa A, Ito J. Apoptosis in retinal ganglion cell decrease in human glaucomatous eyes. Jpn J Ophthalmol 1997;41:84-8.

26 Hollstein M, Rice K, Greenblatt MS, Soussi T, Fuchs R, Sorlie T, Hovig E, Smith-Sorensen B, Montesano R, Harris CC. Database of p53 gene somatic mutations in human tumors and cell lines. Nucleic Acids Res 1994;22:3551-5.

27 Anonymous. Freely associating. Nat Genet 1999;22:1-2.

28 Vieland VJ. The replication requirement. Nat Genet $2001 ; 29: 244-5$. 


\section{PostScript}

\section{BOOK REVIEWS}

\section{Corneal dystrophies and degenerations: a molecular genetics approach}

Edited by $M X$ Wang. Oxford: Oxford University Press, 2003, £67.50. ISBN 0-19516881-X (paperback)

The corneal dystrophies represent a large and varied group of inherited conditions, and the underlying molecular basis of many has been elucidated over the past decade or so. This exciting progress has been rapid and now allows a re-evaluation of our clinical and morphological classifications. This monograph has been produced in association with the American Academy of Ophthalmology, and is published by Oxford University Press. The major body of the text comprises six chapters and a total of 123 pages. In addition there is a short self-study examination directed towards US CME accreditation. As would be expected from such a collaboration, the production qualities are high. Dr Wang, the editor, is a clinical academic in Nashville with major interests in the cornea, external eye disease, and refractive surgery. He lists the book's educational objectives: to bridge the gap between the new molecular information and the knowledge base for today's ophthalmologists; to discuss current understanding of the molecular pathogenesis of these conditions; to outline the use of excimer laser for the treatment of corneal diseases; and to review the most recent literature on corneal dystrophies and degenerations. This monograph, and its two first objectives in particular, are therefore timely in their conception.

The editor is co-author of five of the six chapters. The first chapter, written in collaboration with Dr Francis Munier, discusses the inheritance patterns of the corneal dystrophies, and in particular covers the range of epithelial and stromal dystrophies caused by defects in TGFBI/BIGH3, including a detailed and well constructed examination of their molecular pathology. The following three chapters describe, respectively, the epithelial, stromal, and endothelial dystrophies. In general the clinical, histopathological, and ultrastructural features of the disorders are clearly described, illustrated, and referenced. Here, the molecular focus is generally on gene identification and, whereas for certain disorders-for example, Meesmann epithelial dystrophy-there is a clear description of the underlying molecular mechanisms, this is disappointingly covered for many conditions. The final two chapters, concerning corneal and conjunctival degenerations and excimer laser therapies for corneal dystrophies, are likely to be of limited interest to the geneticist and carry little molecular information.

The key difficulty, when producing a monograph such as this, is ensuring that what is produced is as recent as possible and is not simply a replication of information that is available in other ophthalmological texts. In the first regard, the book unfortunately appears to have taken a disappointingly long time from completion to publication. However, the degree of illustration-all figures are included on the excellent CD ROM that accompanies the book-when allied to the molecular details ensures that the phenotypic descriptions of the dystrophies are covered in a manner that will be both familiar and useful for ophthalmic clinicians and trainees alike.

Conflicts of interest: none declared

G C M Black

\section{Nucleotide and protein expansions and human disease}

Edited by J Gecz, G R Sutherland. Basel: Karger publishers, Reprint of Cytogenetic and Genome Research Vol 100 Nos 1-4, 2003, $£ 67.50$, pp 298. ISBN 3-8055-7621-8 (hardback)

Since 1991, when the CAG repeat expansion causing spinobulbar muscular dystrophy and the CCG repeat expansion in fragile $\mathrm{X}$ syndrome were discovered, there has been great progress in understanding the biology of triplet repeat instability and the diseases associated with these types of mutation. The number of diseases and classes of mutations has grown such that there are currently nine CAG repeat diseases where the repeats are translated into polyglutamine tracts, a recessive triplet mutation (Friedreich's ataxia), more than a handful of different diseases caused by expanded polyalanine tracts (for example, oculopharyngeal muscular dystrophy), diseases associated with untranslated triplet repeats (for example, myotonic dystrophy), and diseases caused by expansion of other micro or minisatellites (for example, progressive myoclonus epilepsy).

Soon after the first group of triplet repeat mutations was discovered, the biological mechanism was revealed behind the previously baffling (and controversial) phenomenon of anticipation, where the disease tends to increase in severity or present at an earlier age in successive generations in families. In many cases there has been rapid progress in developing cell and animal models of disease, and in some cases we have a much better understanding of pathogenesis. Yet many mysteries and controversies remain, even for diseases where the mutation was identified a decade or so ago (for example, myotonic dystrophy and Huntington's disease) and cures and treatments for the human diseases are still elusive.

This book addresses certain aspects of the field with a collection of freestanding articles covering aspects ranging from trinucleotide repeat instability, through epidemiology of spinocerebellar ataxias, to pathogenetic mechanisms. The nature of the book means that there are sometimes issues that are duplicated between chapters. This is not a problem, as the book is probably not designed to be read from cover to cover, but rather as a reference source. The topic coverage is not complete and gaps include discussions of the pathogenesis of Friedreich's ataxia and spinocerebellar ataxia type 1 (both where considerable progress has been made). However, in contrast to many other books where there are collections of chapters, for instance focused on neurological diseases, this book deals with some of the more esoteric areas very well. There are fine chapters on repeat instability (by Lenzmeier and Freudenreich; and by Cleary and Pearson), oculopharyngeal muscular dystrophy (Brais) and on transgenic models of myotonic dystrophy (Wansink and Wieringa), spinobulbar muscular dystrophy (Sobue and colleagues), Huntington's disease (Hickey and Chesselet) and Fragile X syndrome (Bakker and Oostra). It was good to see a chapter devoted to the interesting and possibly under recognised cerebellar ataxia syndrome associated with FRAXA premutation carriers (Hagerman et al) and the excellent chapter on SCA3 by Kobayashi and Kakizuka (a group that have made a number of key contributions to the polyglutamine disease field). In general, the chapters are written by authorities in their fields (including Brice, Ashizawa, Margolis, La Spada, Nelson, Usdin, and Ranum).

In conclusion, this book includes many chapters that add to and complement existing texts dealing with these diseases. The articles are generally of a high standard and are concisely written. This book would be of particular value to human geneticists, genetic counsellors, and researchers working on this class of diseases.

D C Rubinsztein

\section{CORRECTIONS}

doi: 10.1136/jmg.2002.005546corr 1

The acknowledgements for the original article by Bentley et al (J Med Genet 2003;40:24956) were omitted and should read:

\section{Acknowledgements}

We thank Dr Katariina Hannula and Prof Juha Kere for preliminary allelic expression analysis of CPA genes in lymphoblastoid cell lines. We also thank the Dunhill Medical Trust, the WellcomeTrust (LB, ZB, FK), the MRC (DM, JP, CB), and the Canadian Institutes of Health Research (CIHR) for supporting this research. K Nakobayashi is a Research Fellow of the CIHR and S W Scherer is a Scientist of the CIHR and the International Scholar of the Howard Hughes Medical Institute. All animal studies were carried out under the guidance issued by the Medical Research Council (MRC) in The Use of Animals for Medical Research (July 1993) and Home Office Project Licence No 30/1517.

We apologise for this error.

\section{doi: 10.1136/jmg.2004.016089corr 1}

Ressiniotis T, Griffiths P G, Birch M, et al Primary open angle glaucoma is strongly associated with a specific $p 53$ gene haplotype (J Med Genet 2004;41:296-8). An erratum has been detected in the second paragraph of the Key points box. In the penultimate sentence "arginine residue" and "proline residue" should have been transposed. The authors apologise for this error. 